\title{
The electrophysiological and contractile responses of hypertrophic cardiomyopathic myocardium
}

\author{
D. J. Coltart
}

WE have been studying the electrophysiological and contractile responses of small tissue strips excised from the left ventricular outflow tract of two patients with hypertrophic obstructive cardiomyopathy (HOCM). The tissue was excised at cardiac surgery to relieve the outflow-tract pressure-gradient. After the tissue was excised it was gently placed into a vacuum flask containing normal tyrode solution and transported as quickly as possible to our laboratory at St Bartholomew's Hospital. The small strips of the tissue were prepared as previously described (Coltart \& Meldrum, 1971; Coltart, Spilker \& Meldrum, 1971) in order to study the electrophysiological and contractile responses under physiological conditions. The HOCM tissue, which does not beat spontaneously, was stimulated by bipolar platinum electrodes and individual myocardial cells were impaled with a glass micro-electrode of tipdiameter $0.5 \mu \mathrm{m}$ under high powered microscopic control with the aid of a micromanipulator. The action potential thus obtained is displayed on an oscilloscope screen and a camera records the trace from the screen (Fig. 1). The contractile responses are measured by means of a strain gauge. We have observed standard electrophysiological terms as described by Hoffman \& Cranefield, 1960. We found no evidence of pacemaker activity in tissue from adult patients with HOCM which is similar to our experience with human myocardium (Coltart \& Meldrum, 1972) but contrasts with our findings with human foetal myocardium (Coltart et al., 1971). In order to make a critical appraisal of the action potential found in cardiomyopathic tissue we have taken as our control values the records obtained from the left ventricular papillary muscle obtained from patients undergoing mitral valve replacement or tissue excised from the right ventricular infundibulum of patients with Fallot's tetralogy. There is no statistically significant difference between the various electrophysiological parameters of these two groups of 'control' tissue and so I will refer to them as our control action-potential.

Figure 2 shows a 'control' action potential taken from a patient with chronic rheumatic heart disease undergoing mitral valve replacement. We characteristically found that repolarization of the human cardiac action-potential is all one steady downstroke

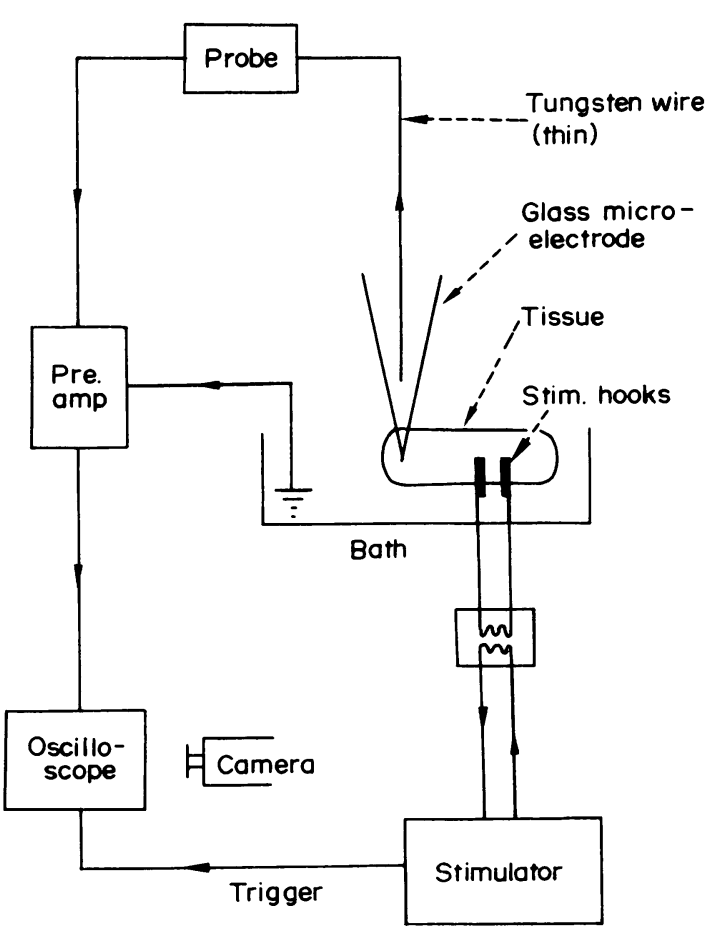

FIG. 1. Diagrammatic representation of method of recording transmembrane potential.

with no readily discernible different phases of repolarization, unlike the action-potential of other species. However, we have previously discussed these differences (Coltart \& Meldrum, 1972). Figure 3 demonstrates the action-potential obtained from patients with HOCM.

A comparison of the electrophysiological properties of the ventricular papillary muscle and the HOCM muscle is given in Table 1 . The repolarization time is increased from $302 \pm 11.2 \mathrm{msec}$ (control tissue) to $498 \pm 29 \mathrm{msec}(P<0.001)$ by a prolongation of the slow phase of repolarization. The maximum rate of rise of the cardiomyopathic tissue was significantly reduced $(P<0 \cdot 001) 186 \pm 12 \mathrm{msec}$ compared with $240 \pm 17 \mathrm{msec}$ in the control studies. All 
TABLE 1. The difference between the action-potentials of the hypertrophic cardiomyopathic and control human cardiac cell

\begin{tabular}{lccccc}
\hline & $\begin{array}{c}\text { Time to } \\
\text { repolarize } \\
\text { to } 90 \% \\
(\mathrm{msec})\end{array}$ & $\begin{array}{c}\text { Resting } \\
\text { potential } \\
(\mathrm{mV})\end{array}$ & $\begin{array}{c}\text { Magnitude } \\
\text { of action } \\
\text { potential } \\
(\mathrm{mV})\end{array}$ & $\begin{array}{c}\text { Maximum } \\
\text { Overshoot } \\
(\mathrm{mV})\end{array}$ & $\begin{array}{c}\text { upstroke } \\
\text { velocity } \\
(\mathrm{v} / \mathrm{sec})\end{array}$ \\
\hline $\begin{array}{l}\text { Control } \\
\text { Hypertrophic } \\
\text { cardiomyopathy }\end{array}$ & $302 \pm 11 \cdot 2$ & $95 \pm 6 \cdot 2$ & $117 \pm 6 \cdot 5$ & $21 \pm 2 \cdot 3$ & $240 \pm 17$ \\
\hline
\end{tabular}

Control $=$ Mean + SD of eighteen tissue studies of left ventricular papillary muscle. Hypertrophic cardiomyopathy $=$ mean $\pm S D$ of ten separate cells of excised muscle.

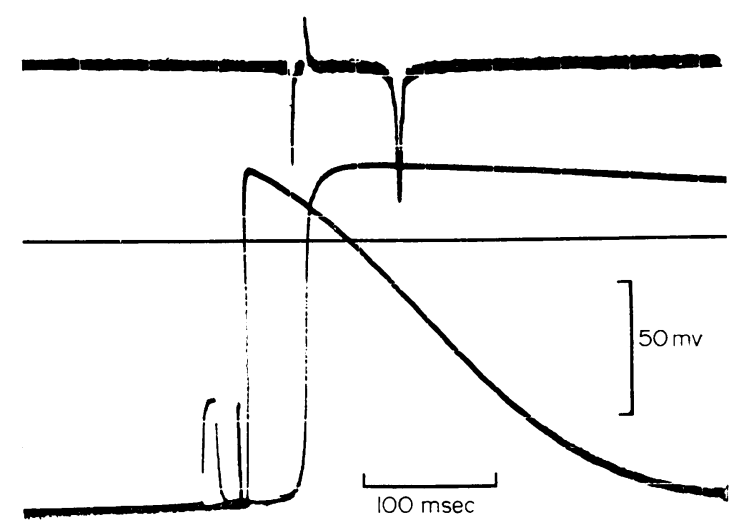

Fig. 2. Typical human (control) ventricular transmembrane action-potential. The horizontal line indicates zero potential; the superimposed middle traces depict intracellular potentials at slow and fast sweep speeds. The upper trace first shows the stimulus artefact followed by the output from the differentiator; the depth of the spike is proportional to $d v / d t$ of the intracellular record.

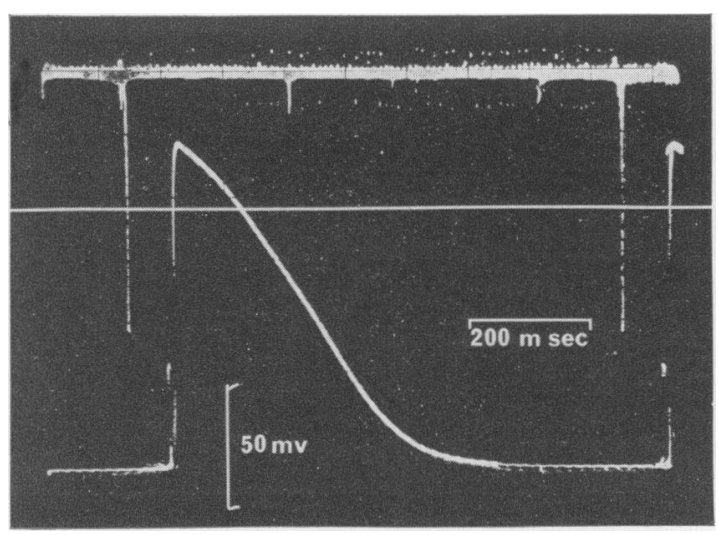

Fig. 3. Typical hypertrophic obstructive ventricular transmembrane action potential. Same notation as Fig.1. other measurements were similar to the "control' values.

Figure 4 shows the contractile response and simultaneously action-potential from a case of HOCM ; the development of maximal tension was slower than in the 'control' tissue. The 'control' tissue maintained its developed tension at increasing frequency of stimulation until around 160 stimulations/min, after which there was a decrease in force.

Figure 5 compares the force-interval curves of the myopathic and control tissue. Over the higher frequency range there was a decrease in the force of the HOCM tissue. Figure 6 shows the trace of the contractile response at a stimulation rate of $144 / \mathrm{min}$ where a phasic pattern of force is demonstrated Figure 7 shows that the concentration of propranolof $(10 \mathrm{mg} / 1)$ needed to demonstrate a non-specific effect in vitro (Coltart \& Meldrum, 1970) caused a similar alteration in the force-frequency relationship of the myopathic and 'control' tissue. This result confirms the view that the sole therapeutic role of propranolol is due to its beta-receptor antagonism and no additional benefit accrues from its non-specific properties (Coltart \& Shand, 1970).

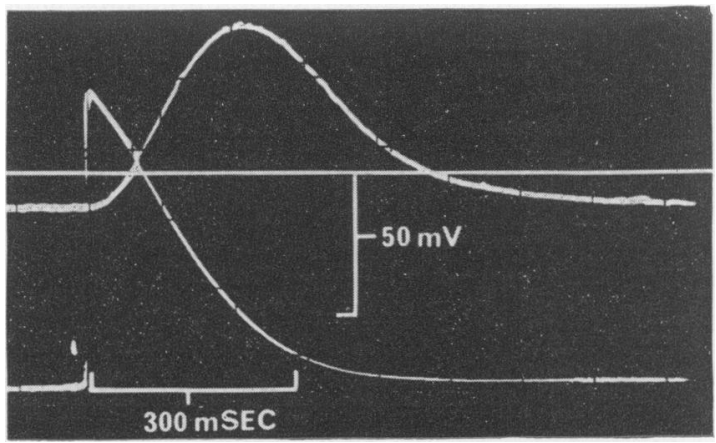

Fig. 4. Simultaneous action potential (lower trace) and contractile response (upper trace). Maximum tension after $220 \mathrm{~m} / \mathrm{sec}$. Straight horizontal line indicates resting potential. 


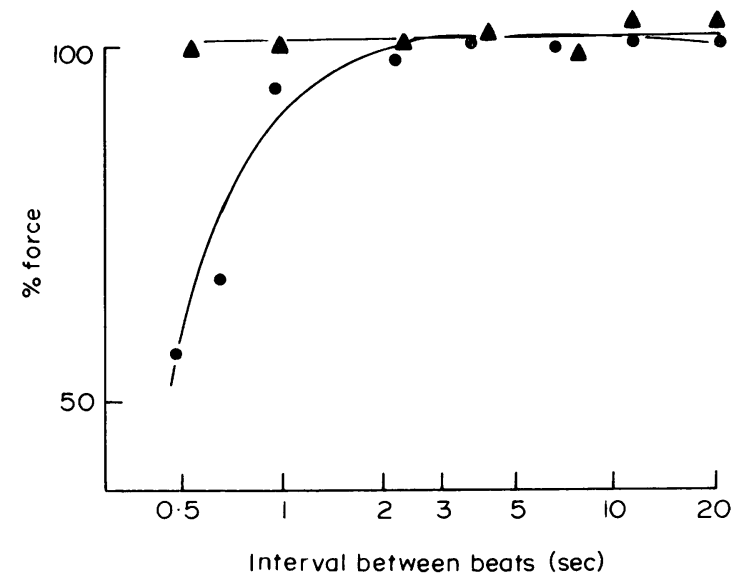

FIG. 5. Force-interval curves for cardiomyopathy and control myocardium. $100 \%$ force represents resting tension. Cardiomyopathy; $\boldsymbol{\Delta}$, control.

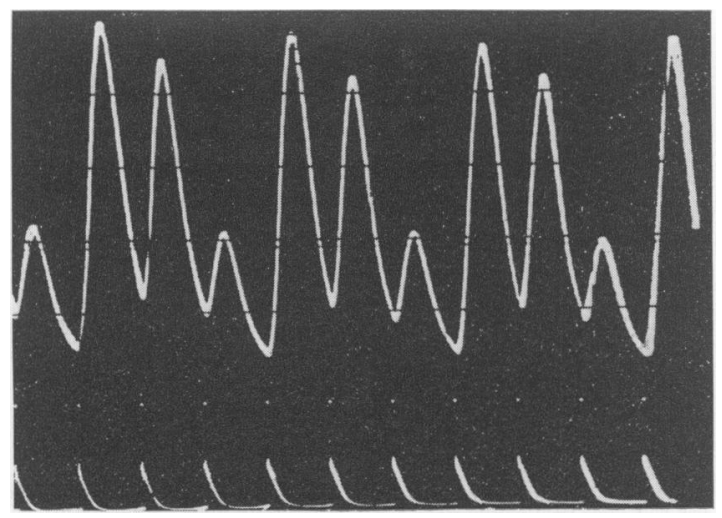

FIG. 6. The upper trace shows the phasic alteration of contractile response when the tissue was stimulated at $144 / \mathrm{min}$. The lower trace depicts the action potential.

\section{Comment}

What is the significance of these findings? The contractility of most mammalian cardiac muscle in vitro is the result of two independent phenomena. Their contribution to the overall contractility varies according to the frequency of stimulation. At high frequencies it is furnished almost entirely by the Bowditch or the staircase phenomenon with an increased strength or an increase in contractile response with increase in frequency of stimulation, whereas the Woodworth phenomenon shows an increase in strength developed with a decrease in frequency. Since the heart rate in vivo is in the range of stimulation called 'high frequency' under in vitro conditions, the importance of the Bowditch phenomenon in support of life is overwhelming.

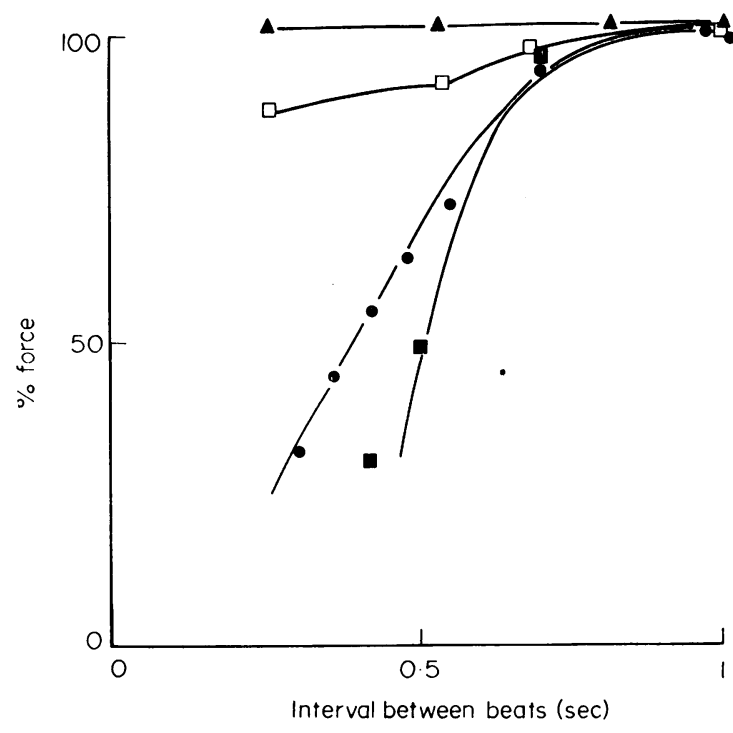

Fig. 7. The effect of $10 \mathrm{mg} / \mathrm{l}$ propranolol on forcefrequency curves. Material from HOCM, $\square$; control, $\square$. After propranolol;, $\mathrm{HOCM} ; \boldsymbol{\Delta}$, control.

An opportunity was presented to study the effect of cardiomyopathy on the contractile response of tissue slices with the development of a strain of hamsters with a hereditary primary congestive cardiomyopathy. Hajdu \& Posner (1971) studied the interval-tension relationship of right ventricular muscles of normal hamsters compared with that of hamsters with hereditary cardiomyopathy, with or without congestive heart failure. The contractility of the heart of animals with cardiomyopathy without circulatory insufficiency did not differ from that of the normal animals at any frequency. The cardiac muscle of animals with severe congestive heart failure showed normal contractility at a low frequency of stimulation (range of Woodworth phenomenon) but did not show the increased contractility upon high frequency stimulation (Bowditch phenomenon) seen in all other animals: this was similar to the response we found with the HOCM tissue. Ryanodine, a neutral alkaloid which decreases the subcellular calcium concentration, eliminates only the contractility caused by the Woodworth phenomenon in the normal myocardium but abolishes the contractility of the hearts of animals with congestive failure over the whole frequency range. Cardiac glycosides, which are known to potentiate the Bowditch phenomenon were ineffective on the cardiac muscle of animals without Bowditch phenomenon. Extrapolating this finding to our human data a similar lack of inotropic effect from the glycosides would be expected. This means that at 
the terminal phase of cardiomyopathy when the glycosides are needed for their therapeutic effect, their effectiveness, as has been found clinically, seems to be lowest (Burch \& De Pasquale, 1968). This observation is not readily appreciated in clinical practice because such patients are generally medicated with beta-blocking agents and thus the natural history of the disease is confused. (a)

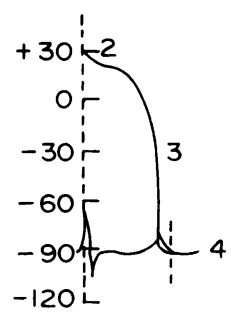

Control

(d)

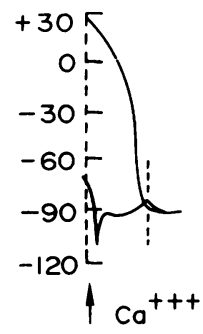

(b)

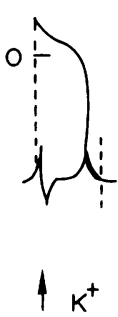

(e)

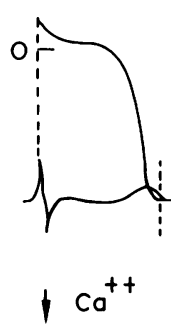

(c)

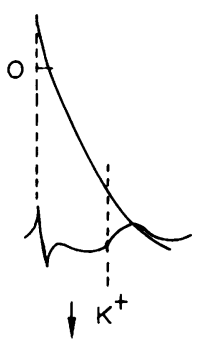

(f)

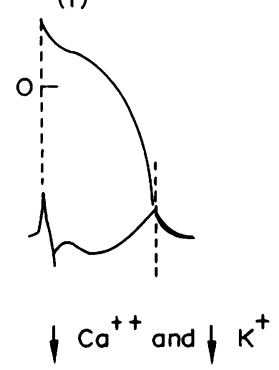

FIG. 8. A schematic diagram of ventricular transmembrane action-potential and the electrocardiogram. The numbers on the left indicate the values of the membrane potential $(\mathrm{mV})$. The dashed vertical line designates the end of ventricular systole.

How can we explain these changes on our current knowledge of altered electrolyte fluxes causing alterations in the action potentials? Figure 8 shows the electrocardiograph associated with the actionpotential when the extracellular ionic concentration is altered. A block in the normal potassium transmembrane permeability would delay repolarization and prolong the refractory period. A restraint on potassium permeability, however, would be expected to reduce the resting potential but this was unchanged in the present study. Hypocalcaemia increases the duration of repolarization of the action-potential mainly by prolonging the rapid early phase of repolarization and only to a lesser extent the slower and later phase as seen in the cardiomyopathic tissue. The effect of hypocalcaemia would be exaggerated by hypomagnesaemia. It seems unlikely that an abnormal transmembrane perme- ability of any one of these electrolytes could explain the observed action-potential but a combination of a deficient flux of all three could be postulated.

Turning now to other conditions which show this abnormality in the action-potential of a gross prolongation of repolarization; Vaughan Williams (1971) has classified this into his third grade of drug-effects on the action potential. Hypothyroidism (Freedberg, Papp \& Vaughan Williams, 1970) and the compounds, amiodarone (Singh \& Vaughan Williams, 1970a) and MJ 1999 (Singh \& Vaughan Williams, 1970b) produce similar effects. It should be emphasized that the patients in this study were euthyroid.

In conclusion, this is a preliminary report of a constant and characteristic change we have found in both the electrophysiology and contractile response of myocardial tissue from patients with hypertrophic obstructive cardiomyopathy. As the vogue for surgical myectomy in such patients has become rare in London our desire to extend this study has not been readily fulfilled.

\section{References}

Burch, G.E. \& De Pasquale, N.P. (1968) Heart Muscle Disease. Disease-a-Month, p. 59. Year Book Medical Publishers, Inc., Chicago.

ColtarT, D.J., \& Meldrum, S.J. (1970) The effect of racemie propranolol on the human and canine transmembrane action potential. British Journal of Pharmacology, 40, 148.马

ColtarT, D.J. \& MeldRum, S.J. (1971) The effects of racemic, dextro-propranolol and racemic practolol on the human and canine transmembrane action potential. Archives internationales de pharmacodynamie et de thérapie, 192, 188.

ColtarT, D.J. \& Meldrum, S.J. (1972) Comparison of the transmembrane action potential of the human and canine myocardium. Cardiology (in press).

ColtarT, D.J. \& Shand, D.G. (1970) Plasma propranolol levels in the quantitative assessment of beta-adrenergic blockade in man. British Medical Journal, 3, 731.

Coltart, D.J., Spilker, B.A. \& Meldrum, S.J. (1971) The electrophysiology of human foetal cardiac muscle. Experienta, 27, 797.

Freedberg, A.S., Papp, J. Gy. \& Vaughan Williams, E.M. (1970) The effect of altered thyroid state on atrial intracellular potentials. Journal of Physiology, 207, 357.

HaJdu, S. \& Posner, C.J. (1971) Absence of Bowditch phenomenon in the ventricular muscle of hamsters with hereditary cardiomyopathy. American Heart Journal, 81, 781.

Hoffman, B.F. \& Cranefield, P.F. (1960) Electrophysiology of the Heart. McGraw-Hill Book Co., New York.

Singh, B.N. \& Vaughan Williams, E.M. (1970a) The effect of amiodorone, a new anti-anginal drug, on cardiac muscle. British Journal of Pharmacology, 39, 657.

Singh, B.N. \& Vaughan Williams, E.M. (1970b) A third class of anti-arrhythmic action. Effects on atrial and ventricular intracellular potentials, and other pharmacological actions on cardiac muscle, of MJ 1999 and AH 3474. British Journal of Pharmacology, 39, 675.

Vaughan Williams, E.M. (1970) The classification of antiarrhythmic drugs. In: Symposium on Cardiac Arrhythmias (Ed. by E. Sandie, E. Flensted-Jensen and K. H. Oleson). A. B. Astra, Södertäljg, Sweden. 